\section{Trusts and Foundations}

A Select Guide to Organizations and Grant-making Bodies Operating in Great Britain and the Commonwealth. Compiled by Guy W. Keeling. Edited by Thomas Landau. Pp. xi +194 . (Cambridge: Bowes and Bowes Publishers, Ltd., 1953.) 42s. net.

$\mathrm{N}$ the foreword to this book, Lord Nathan, formerly 1 chairman of the Committee on the Law and Practice relating to Charitable Trusts, points out that, though the Charitable Trusts Act has been in operation for a hundred years, this year being in fact its centenary, yet no one, not even the Charity Commissioners, can say with precision how many charitable trusts exist in England and Wales. The figure given to Lord Nathan's Committee is eleven thousand; but it is generally agreed that the actual number is greater. The present work gives a selection of a thousand bodies within Great Britain and the British Commonwealth that afford grant-aid, with information supplied by them regarding their resources and activities. Each body is given a separate paragraph, and they are listed in alphabetical order, the whole taking up more than threequarters of the book. The rest of the space consists of a classified index arranged according to the Dewey Decimal Classification, an alphabetical subject index, an appendix of grants made by government depart. ments to voluntary agencies, and a bibliography, this last-named being divided into a list of local directories arranged by county and town, and a list of publications arranged by subject. The value of this guide as a whole lies principally in the amount of time that it will save, both for applicants and for the body that is approached. In spite of the increased amount of money that is nowadays forthcoming from the State, there is still a need for these private trusts, for, as many a research worker will testify, they perform a valuable service in many fields of scholarship and welfare. So long as they continue, it is essential that those seeking grants should know which is the appropriate body to turn to, and this book is a modest start in regard to providing such information.

Common Ocean Fishes of the Californian Coast Fish Bulletin No. 91 of the Marine Fisheries Branch, Department of Fish and Game, State of California. By Phil M. Roedel. Pp. 183. (San Francisco: Dept. of Fish and Game, 1953.) n.p.

T HIS bulletin is designed as a guide to those marine fishes of California that are likely to be caught by commercial and sporting fishermen. Deep-sea fishes and the small forms from inshore waters that rarely, if ever, enter the fishermen's catches are not included. This guiding precept of likelihood of capture by fishermen has resulted in the inclusion of some species that are actually quite rare in California and the exclusion of some ordinarily common ones. The bulletin is meant for everyone interested in fishes regardless of his technical background, and scientific terminology has been kept to a minimum. Such terms as do appear are defined in a short glossary.

A brief description of each species is accompanied (with only a few exceptions) by a photographic illustration of an adult fish. Most of the illustrations are of a reasonably high standard; but a few-of admittedly difficult subjects-are disappointingly poor. Notes on fishing seasons and fishing gear are also provided. In addition to its scientific name, each fish is given what is described as an "official" common name. 'These "official" common names have been assigned by the Department of Fish and Game of the State of California in order to obtain reasonable consistency in terminology-an essential in the collection of accurate statistical and other information.

An identification key is included for the more common species. Such an incomplete key is often more of a hindrance than a help to the unwary novice who tries to identify a specimen that is not in the key. How is he to know whether his failure to name his fish is due to its omission from the key or to his having 'taken a wrong turning' somewhere ? To be of real use a key must contain all the species likely to turn up. This, however, is a small point-and keys are notoriously difficult to compile, anyway.

\section{A University Text-Book of Physics}

Vol. 3 : Heat. Being the eleventh edition and a largely rewritten version of Poynting and Thomson's "Text-Book of Physics", Vol. 3. Pp. $x+439$. (London : Charles Griffin and Co., Ltd., 1952.) 36s. net.

THE publication of this book raises an interesting question. Can a text-book which was brilliantly successful thirty years ago be successfully revised for the present generation of students? The reviewer regretfully feels that the answer must be 'no'. Mr. J. H. Awbery has made a valiant attempt to bring the material up to date; but there is no doubt that, during the past thirty years, the scope of physics teaching in the universities has vastly changed (for better or worse), and much of what appears in this book is now of pre-university standard. In the final chapters, on thermodynamics, where the revision has been greatest, modern standards are adhered to ; but then there are other books (including Mr. Awbery's own) which deal successfully with this part of the subject.

In the reviewer's opinion, therefore, it is wiser to leave the classics as they were written for their own times, and to allow the present generation of authors to produce their own text-books in their own way. H. L.

\section{Weather Inference for Beginners}

Made clear in a Series of Actual Examples. By D. J. Holland. Pp. xiv + 196. (Cambridge: At the University Press, 1953.) 30s. net.

TN this book the author adopts the novel idea of taking the weather-changes over a sequence of days (in the autumn and winter of 1936) as he observed them in London with the simple apparatus available to a boy, and using them as the text for a series of simple explanations of the physical processes in the atmosphere which caused them. Both physics and meteorology are fairly advanced but should be quite intelligible to most readers, except perhaps where vectors are introduced, and this part of the book should be very useful to science teachers in schools where weather records are kept. Later, the observations are related to simplified synoptic charts of western Europe for the same period, and the reader is introduced to anticyclones, depressions and fronts. The remarks on frontal analysis should be of value to young entrants to the meteorological services learning the elements of weather forecasting, as also should be the concluding chapter on upper-air analysis, use of analogues and other aspects of practical forecasting. The chief difficulty, for the readers for whom the book is intended, is likely to be the high price, due no doubt to the lavish production. 